Article

\title{
Etiology of Minor Troponin Elevations in Patients with Atrial Fibrillation at Emergency Department-Tropo-AF Study
}

\author{
Samuli Jaakkola ${ }^{1,+}{ }^{+}$, Tuomas Paana ${ }^{1,+}$, Ilpo Nuotio ${ }^{1,2}$, Tuomas O. Kiviniemi ${ }^{1,3}$, \\ Jussi-Pekka Pouru ${ }^{1}\left(\mathbb{D}\right.$, Pekka Porela ${ }^{1}$, Fausto Biancari ${ }^{1,4}{ }^{(D)}$ and K. E. Juhani Airaksinen ${ }^{1, *(D)}$ \\ 1 Heart Center, Turku University Hospital and University of Turku, 20521 Turku, Finland; \\ samuli.jaakkola@tyks.fi (S.J.); tuomas.paana@tyks.fi (T.P.); ilpo.nuotio@tyks.fi (I.N.); tuoski@utu.fi (T.O.K.); \\ jussi-pekka.j.pouru@utu.fi (J.-P.P.); pekka.porela@tyks.fi (P.P.); fausto.biancari@tyks.fi (F.B.) \\ 2 Department of Acute Internal Medicine, Turku University Hospital and University of Turku, \\ 20521 Turku, Finland \\ 3 Cardiovascular Medicine, Brigham and Women's Hospital, Harvard Medical School, Boston, MA 02115, USA \\ 4 Research Unit of Surgery, Anesthesiology and Critical Care, University of Oulu, 90014 Oulu, Finland \\ * Correspondence: juhani.airaksinen@tyks.fi; Tel.: +358-2-3131005 \\ + Equal contribution.
}

Received: 16 October 2019; Accepted: 10 November 2019; Published: 14 November 2019

\begin{abstract}
Patients with atrial fibrillation (AF) presenting to the emergency department (ED) often have elevated cardiac troponin $\mathrm{T}(\mathrm{TnT}$ ) levels without evidence of type 1 myocardial infarction. We sought to explore the causes and significance of minor TnT elevations in patients with AF at the ED. All patients with AF admitted to the ED of Turku University Hospital between 1 March, 2013 and 11 April, 2016, and at least two TnT measurements, were screened. Overall, 2911 patients with a maximum TnT of $100 \mathrm{ng} / \mathrm{L}$ during hospitalization were analyzed. TnT was between 15 and $100 \mathrm{ng} / \mathrm{L}$ in 2116 patients. The most common primary discharge diagnoses in this group were AF (18.1\%), infection (18.3\%), ischemic stroke/transient ischemic attack (10.7\%), and heart failure $(5.0 \%)$. Acute coronary syndrome (ACS) was equally uncommon both in patients with normal TnT and elevated $\operatorname{TnT}(4.4 \%$ vs. $4.5 \%)$. Age $\geq 75$ years, low estimated glomerular filtration rate (eGFR), high C-reactive protein (CRP), and hemoglobin $<10.0 \mathrm{~g} / \mathrm{dL}$, were the most important predictors of elevated TnT. Importantly, TnT elevation was a very frequent $(>93 \%)$ finding in elderly ( $\geq 75$ years) AF patients with either low eGFR or high CRP. In conclusion, minor TnT elevations carry limited diagnostic value in elderly AF patients with comorbidities.
\end{abstract}

Keywords: troponin; atrial fibrillation; acute coronary syndrome

\section{Introduction}

Approximately $10-40 \%$ of patients with atrial fibrillation (AF) are hospitalized annually and this proportion is expected to rise in the near future [1]. Cardiac troponin measurements have become a part of routine laboratory work-ups in the emergency department (ED) in various clinical scenarios. A common diagnostic challenge with AF patients is the exclusion of type 1 myocardial infarction (MI), referring to infarction caused by plaque rupture, erosion, and/or dissection in coronary arteries, as opposed to type $2 \mathrm{MI}$, which refers to a mismatch between oxygen supply and demand [2]. The advent of high-sensitive troponin assays enables early detection of acute MI, however, at a cost of false positive diagnoses. Minor troponin elevations are common in a wide variety of medical conditions, such as systemic infection, pulmonary embolism, renal failure, cerebrovascular accident, heart failure, and even after extreme physical stress [3-10]. This multiplicity of causes is problematic in 
acute care decision-making when the main goal is to detect or rule out type $1 \mathrm{MI}$ as the cause of the ED visit and troponin elevations.

Troponin elevation is common in AF [11-13] and patients with AF are a common patient group at the ED. Since little is known about the causes of mild troponin elevations in this scenario, we sought to assess the frequency of various discharge diagnoses in AF patients with minor (15-100 ng/L) cardiac high-sensitivity troponin $\mathrm{T}$ (TnT) elevations. Secondly, we sought factors differentiating AF patients with the clinical diagnosis of acute coronary syndrome (ACS) from patients with other causes for minor TnT elevations.

\section{Materials and Methods}

This study reports the main results from the Troponins in Atrial Fibrillation study (The Tropo-AF Study, ClinicalTrials.gov Identifier: NCT03683836), which belongs to a series of study protocols assessing clinical challenges in the treatment of AF [5,14-16].

The study protocol was approved by the Medical Ethics Committee of the Hospital District of Southwest Finland. Informed consent was not required because of the observational nature of the study. The study complies with the Declaration of Helsinki as revised in 2002.

Initially, database searches were performed to identify patients whose TnT levels were measured between 1 March, 2013 and 11 April, 2016 at the Turku University Hospital laboratory. This initial screening lead to a total of 145,837 individual TnT measurements. Patients with a prior diagnosis of AF (ICD-10 code I48) or AF diagnosed at the index visit, living in the hospital catchment area, with an admission electrocardiography (ECG), and two serial TnT measurements within 8-72 $\mathrm{h}$ after admission to the ED, were identified. Thereafter, patients with maximum TnT values $<100 \mathrm{ng} / \mathrm{L}$ during the entire hospitalization were selected for the present analysis. Dynamic TnT change was defined as the difference between highest and lowest TnT values recorded during hospitalization, in percentages. Admission ECGs were screened for ST-depression $\geq 1 \mathrm{~mm}$ in two adjacent leads.

The diagnosis of AF (either made before or at the time of the ED visit) was confirmed by 12-lead ECG findings. All individual electronic patient records were reviewed by the investigation group using a standardized protocol to collect specific information on the clinical characteristics of patients, clinical conditions, as well as other clinical and laboratory data of interest from the index hospitalization. Mortality data were retrieved from the national statistical institution, Statistics Finland, and therefore we assumed that no patient was missing at follow-up.

The primary measure of this analysis was an increase of TnT levels between 15 and $100 \mathrm{ng} / \mathrm{L}$ during the hospital visit. TnT was analyzed using a commercial high-sensitive assay (Roche Diagnostics $\mathrm{GmbH}$, Mannheim, Germany) at the hospital's certified laboratory. Determined by the manufacturer, the 99th percentile upper reference limit was $14 \mathrm{ng} / \mathrm{L}$ for the assay. Two study groups were formed on the basis of maximum TnT values-patients with normal $(<15 \mathrm{ng} / \mathrm{L}) \mathrm{TnT}(n=795)$ and those with minor $(15-100 \mathrm{ng} / \mathrm{L}) \mathrm{TnT}$ elevations $(n=2116)$.

This article was prepared following the STROBE guidelines [17] for the reporting of observational studies.

\section{Statistical Analysis}

Statistical analyses were performed using SPSS v.25.0 statistical software (IBM Corporation, New York, NY, USA). Continuous variables are reported as mean and standard deviation (SD) if normally distributed, and as median and interquartile range (IQR) if skewed, unless stated otherwise. Missing data were not replaced. Categorical variables are described as counts and percentages. The chi-square test and Fisher's exact test were used for categorical variables, as appropriate. Logistic regression analysis using the backward Wald method was performed to identify independent predictors of TnT elevations, as well as ACS in patients with elevated TnT. Covariates with $p<0.1$ in univariate analyses were entered into the regression model. All tests were two-sided and statistical significance was set at $5 \%$. 
Classification and regression tree (CART) analysis was performed to identify independent risk factors for TnT elevations. The classification tree procedure was assessed by cross-validation through 25-fold The minimum number of patients for the parent node was set at 100 and the minimum for the child node was 50. Gini's method was used to measure impurity, which is the extent to which a node does not represent a homogenous subset of cases. A minimum change in improvement was set at 0.0001. Normalized importance to the model of the included covariates was estimated. Covariates, which were identified as independent risk factors for TnT 15-100 ng/L in logistic regression and with normalized importance $>20 \%$, were included in the final CART model. The area under the receiver operating characteristic curve (AUC) was estimated to assess the regression model discrimination.

\section{Results}

A total of 2911 AF patients were included in the study and $72.7 \%(n=2116)$ of them had minor TnT elevation, ranging from 15 to $100 \mathrm{ng} / \mathrm{L}$. Patient characteristics according to maximum TnT levels are presented in Table 1 . The most common symptoms at admission were any kind of chest pain (513 cases, $17.6 \%$ ), dyspnea ( 823 cases, $28.3 \%$ ), and malaise/nausea/dizziness (629 cases, $21.6 \%$ ). At hospital discharge, the most common primary diagnostic categories were $\mathrm{AF}(21.6 \%, n=628)$, infections $(14.4 \%$, $n=420)$, ischemic stroke/transient ischemic attack $(13.0 \%, n=378)$, decompensated heart failure $(11.9 \%$, $n=346)$, and ACS $(4.5 \%, n=130)$, comprising $65.3 \%$ of all hospital admissions (Figure 1 and Table S1). Other frequent primary diagnoses were bone fractures, trauma, intoxications, bleeding, renal insufficiency, inflammatory diseases, and various symptomatic diagnoses.

Table 1. Patient characteristics according to troponin T levels at hospital admission.

\begin{tabular}{cccc}
\hline Characteristic & $\begin{array}{c}\text { TnT } \leq \mathbf{1 4} \mathbf{~ n g} / \mathbf{L} \\
(\boldsymbol{n}=\mathbf{7 9 5})\end{array}$ & $\begin{array}{c}\text { TnT 15-100 ng/L } \\
(\boldsymbol{n}=\mathbf{2 1 1 6})\end{array}$ & $p$ \\
\hline Age, median (IQR), y & No. $(\%)$ & No. $(\%)$ & $<0.001$ \\
Women & $72.0(14)$ & $81.0(12)$ & 0.005 \\
CHA $_{2}$ DS ${ }_{2}$-VASc, mean (SD) & $431(54.3)$ & $1026(48.5)$ & $<0.001$ \\
Heart failure & $3.30(1.85)$ & $4.11(1.68)$ & $<0.001$ \\
Hypertension & $86(10.8)$ & $524(24.8)$ & 0.001 \\
Diabetes mellitus & $505(63.5)$ & $1485(70.2)$ & $<0.001$ \\
Prior stroke & $155(19.5)$ & $590(27.9)$ & 0.39 \\
Prior myocardial infarction & $119(15.0)$ & $346(16.4)$ & 0.007 \\
Hypercholesterolemia & $99(12.5)$ & $350(16.5)$ & 0.03 \\
Coronary artery disease & $340(42.8)$ & $811(38.3)$ & $<0.001$ \\
Heart rate at admission, median (IQR), bpm & $186(23.4)$ & $683(32.3)$ & $<0.001$ \\
Systolic blood pressure, median (IQR), mm Hg * & $81(66-102)$ & $87(72-109)$ & 0.002 \\
ST depression in admission ECG *, & $144(126-163)$ & $140(122-160)$ & $<0.001$ \\
Laboratory tests at admission & $42(5.8)$ & $305(15.9)$ & $<0.001$ \\
TnT, median (IQR), ng/L & & & $<0.001$ \\
Hemoglobin, median (IQR), g/dL & $9(6-8(12.8-14.7)$ & $12.8(11.5-14.2)$ & $<0.001$ \\
Creatinine, median (IQR), $\mu$ mol/L & $79.6(70.7-97.2)$ & $97.2(79.6-124)$ & $<0.001$ \\
eGFR, median (IQR), mL/min/1.73 m ${ }^{2}$ & $71.3(58.8-83.8)$ & $55.1(40.0-72.3)$ & $<0.001$ \\
ProBNP, median (IQR), ng/L * & $998(454-2335)$ & $3370(1580-6355)$ & $<0.001$ \\
CRP, median (IQR), mg/L & $3(2-7)$ & $10(3-37)$ &
\end{tabular}

$\mathrm{CHA}_{2} \mathrm{DS}_{2}$-VASc, 1 point each for congestive heart failure, hypertension, diabetes mellitus, vascular disease, age 65-74 years, and female sex, and 2 points for prior stroke, transient ischemic attack, or thromboembolism, and age $\geq 75$ years; CRP, C-reactive protein; eGFR, estimated glomerular filtration rate (calculated using the Chronic Kidney Disease Epidemiology Collaboration equation); TnT, high-sensitivity cardiac troponin T, ProBNP, pro-brain natriuretic peptide. *, The number of patients with missing data for CRP was $n=261(9.0 \%)$, for ST-depression $n=265(9.1 \%)$, for systolic blood pressure $n=352(12.1 \%)$, and for proBNP $n=1507(51.8 \%) .{ }^{\dagger}, \geq 1 \mathrm{~mm}$ ST-depression in two adjacent leads; IQR, interquartile range; SD, standard deviation. 

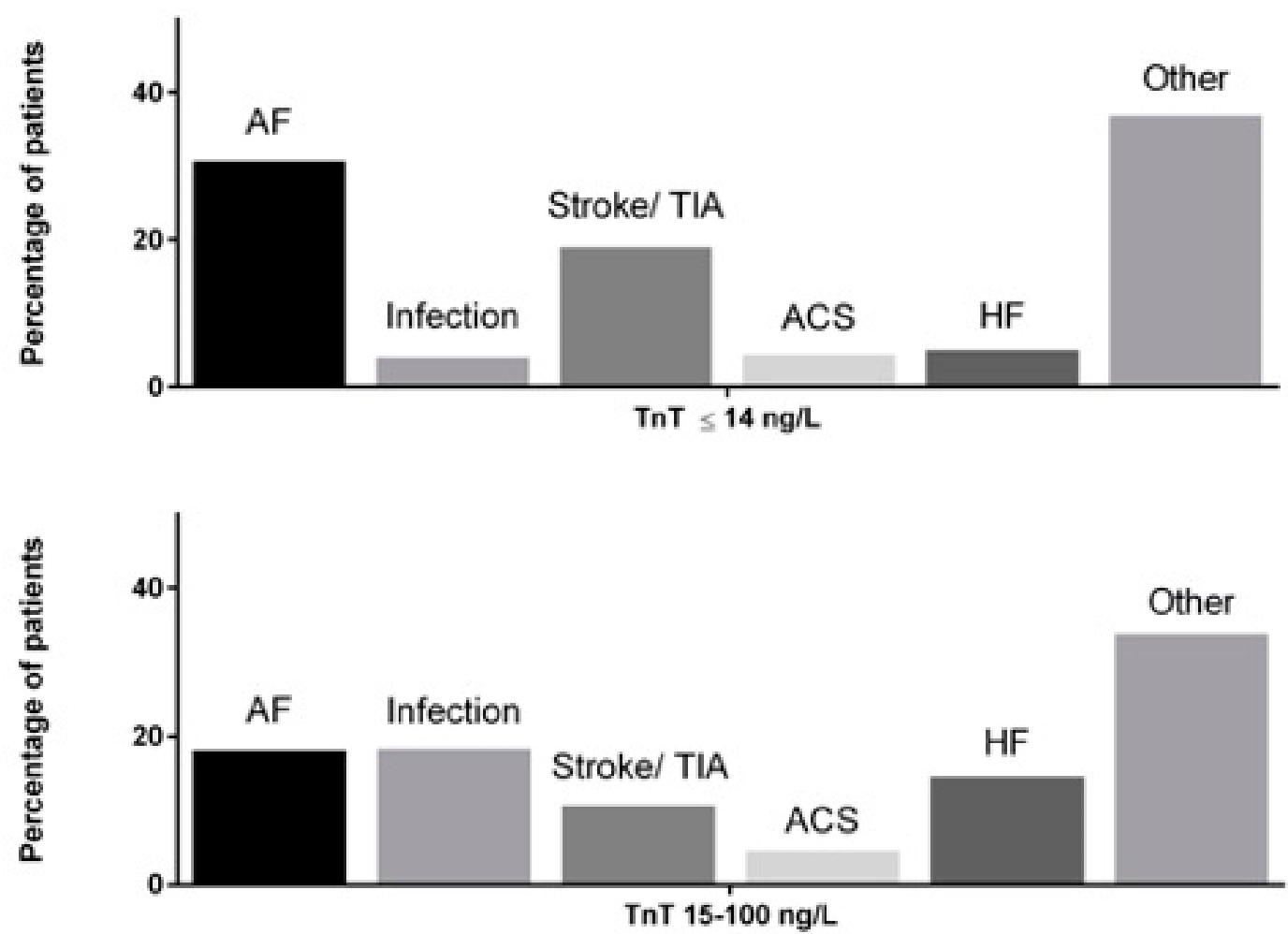

Figure 1. Distribution of different primary discharge diagnoses in patients with normal TnT (top) and minor TnT elevations (bottom). ACS, acute coronary syndrome; AF, atrial fibrillation; HF, heart failure; and TIA, transient ischemic attack. Linear-by-linear association test: statistically significant $(p<0.001)$ differences in distribution of diagnostic categories between $\mathrm{TnT} \leq 14 \mathrm{ng} / \mathrm{L}$ and TnT 15-100 ng/L groups.

Importantly, ACS was an equally uncommon primary discharge diagnosis, both in patients with normal $\operatorname{TnT}$ and minor TnT elevations in the $\mathrm{ED}(4.4 \%, n=35$ vs. $4.5 \%, n=95$, respectively). AF was the most common $(30.7 \%, n=244)$ primary discharge diagnosis of the index hospital visit in patients with normal TnT, whereas severe infections $(18.3 \%, n=388)$ and $\mathrm{AF}(18.1 \%, n=384)$ were the most frequent diagnoses at hospital discharge in patients with minor TnT elevations (Figure 1).

Chest pain was reported by $27.0 \%(n=215)$ of patients with normal TnT, while only $14.1 \%(n=298)$ of those with minor TnT elevations reported chest pain. Among patients with ACS, nearly two-thirds $(65.4 \%, n=85)$ experienced chest pain, but only $12.8 \%(n=38)$ of patients with chest pain and minor TnT rises were diagnosed with ACS. ST-depressions were observed in $10.7 \%$ of patients with ACS and $13.2 \%$ of those with other primary diagnoses. A coronary angiogram was performed in $3.0 \%$ $(n=87)$ of all study patients and in $24.6 \%(n=32)$ of patients with the final diagnosis of ACS. Coronary angiography revealed significant coronary artery disease (>50\% stenosis) in 31 (96.9\%) ACS patients, but resulted in percutaneous coronary intervention in 18 (20.7\%) patients, including two patients with normal TnT values. Patients were selected for coronary angiography based on clinical evaluation by the attending physician.

The strongest independent predictors of minor TnT elevation in the whole patient cohort were age $\geq 75$ years, estimated glomerular filtration rate (eGFR) $<45 \mathrm{~mL} / \mathrm{min} / 1.73 \mathrm{~m}^{2}$, C-reactive protein $(C R P) \geq 50 \mathrm{mg} / \mathrm{L}$, and hemoglobin $<10.0 \mathrm{~g} / \mathrm{dL}$ (Table 2). CART analysis showed that nearly all $(>93 \%)$ patients $\geq 75$ years of age with either high CRP or low eGFR had elevated TnT concentrations (Figure 2). Age $\geq 75$ years (normalized importance, $100 \%$ ), eGFR $<45 \mathrm{~mL} / \mathrm{min} / 1.73 \mathrm{~m}^{2}$ (normalized importance, $57.6 \%$ ), CRP $\geq 50 \mathrm{mg} / \mathrm{L}$ (normalized importance, $30.5 \%$ ), and ST depression $\geq 1 \mathrm{~mm}$ (normalized importance, $21.0 \%$ ), were included in the final CART model. The AUC of this CART model was 0.763 (95\% CI, 0.745-0.782). A CART model not including patients with a diagnosis of ACS confirmed the findings of the overall cohort (AUC $0.763,95 \%$ CI, 0.744-0.782). 


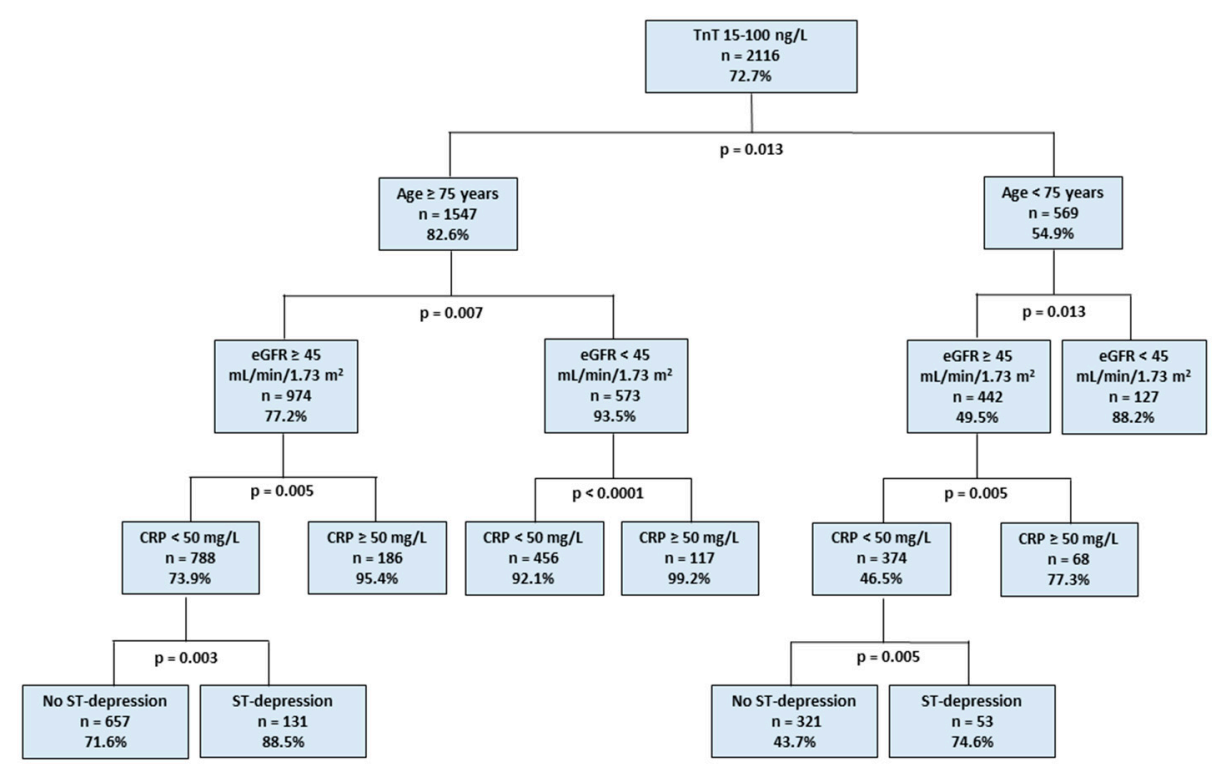

Figure 2. Classification and regression tree analysis showing the independent importance of covariates predicting troponin $\mathrm{T}$ elevations in patients with atrial fibrillation. \%: percentage of patients with TnT 15-100 ng/L among patients with covariates indicated in each box. CRP, C-reactive protein; eGFR, estimated glomerular filtration rate (calculated using the Chronic Kidney Disease Epidemiology Collaboration equation); TnT, high-sensitivity cardiac troponin T. ST-depression: $\geq 1 \mathrm{~mm}$ ST-depression in two adjacent leads.; eGFR, estimated glomerular filtration rate; CRP, C-reactive protein.

In patients with elevated $\mathrm{TnT}$, chest pain (OR 8.29, 95\% CI, 5.20-13.2), previous coronary artery disease (OR 2.33, 95\% CI, 1.42-3.81), and low eGFR (OR 1.65, 95\% CI, 1.04-2.62) were the independent predictors for the final diagnosis of ACS (Table 3), but only $24.1 \%$ of minor TnT elevations in patients with previous coronary artery disease and chest pain were considered to be caused by ACS. A change of at least 100\% in absolute TnT value was observed in $12(12.6 \%)$ patients with ACS and in $146(7.2 \%)$ without ACS, $p=0.068$.

The 30-day mortality was significantly higher in the TnT elevation group compared to the normal TnT group, both in the whole study cohort and in patients with ACS $(8.9 \%$ vs. $0.9 \%$ and $8.4 \%$ vs. $2.9 \%$, $p<0.001$ for both). One ( $0.05 \%)$ patient with elevated TnT and no ACS diagnosis during the index hospitalization was treated for ACS during the 30-day follow-up. 
Table 2. Predictors of troponin T elevation in patients with atrial fibrillation.

\begin{tabular}{|c|c|c|c|c|c|}
\hline Univariable & Odds Ratio $(95 \% \mathrm{CI})$ & $p$ & Multivariable & Odds Ratio $(95 \%$ CI) & $p$ \\
\hline Age $\geq 75$ years & $3.89(3.28-4.62)$ & $<0.001$ & Age $\geq 75$ years & $4.77(3.77-6.04)$ & $<0.001$ \\
\hline Male gender & $1.26(1.07-1.49)$ & 0.005 & Male gender & $2.54(2.01-3.21)$ & $<0.001$ \\
\hline Heart failure & $2.71(2.13-3.47)$ & $<0.001$ & Chest pain & $0.58(0.44-0.76)$ & $<0.001$ \\
\hline Hypertension & $1.35(1.14-1.61)$ & 0.001 & ST depression in admission ECG * & $2.71(1.85-3.97)$ & $<0.001$ \\
\hline Diabetes mellitus & $1.60(1.31-1.95)$ & $<0.001$ & Ventricular rate $\geq 100 \mathrm{bpm}$ at admission & $1.71(1.36-2.17)$ & $<0.001$ \\
\hline Prior stroke or TIA & $0.98(0.80-1.20)$ & 0.83 & $\mathrm{eGFR}<45 \mathrm{~mL} / \mathrm{min} / 1.73 \mathrm{~m}^{2}$ & $5.06(3.58-7.14)$ & $<0.001$ \\
\hline Hypercholesterolemia & $0.83(0.71-0.98)$ & 0.03 & $\mathrm{CRP} \geq 50 \mathrm{mg} / \mathrm{L}$ & $3.79(2.49-5.77)$ & $<0.001$ \\
\hline Coronary artery disease & $1.56(1.29-1.89)$ & $<0.001$ & Hemoglobin $<10.0 \mathrm{~g} / \mathrm{dL}$ & $4.95(2.33-10.55)$ & $<0.001$ \\
\hline Active malignancy & $1.30(0.85-1.98)$ & 0.23 & & & \\
\hline Chest pain & $0.44(0.36-0.54)$ & $<0.001$ & & & \\
\hline ST depression in admission ECG ${ }^{*, \dagger}$ & $3.06(2.19-4.27)$ & $<0.001$ & & & \\
\hline Ventricular rate $\geq 100 \mathrm{bpm}$ at admission & $1.37(1.14-1.64)$ & 0.001 & & & \\
\hline $\mathrm{AF}$ at admission & $1.79(1.51-2.12)$ & $<0.001$ & & & \\
\hline $\mathrm{eGFR}<45 \mathrm{~mL} / \mathrm{min} / 1.73 \mathrm{~m}^{2}$ & $6.40(4.82-8.51)$ & $<0.001$ & & & \\
\hline $\mathrm{CRP} \geq 50 \mathrm{mg} / \mathrm{L}^{+}$ & $5.04(3.46-7.35)$ & $<0.001$ & & & \\
\hline Hemoglobin $<10.0 \mathrm{~g} / \mathrm{dL}$ & $6.19(3.34-11.4)$ & $<0.001$ & & & \\
\hline
\end{tabular}

$\mathrm{AF}$, atrial fibrillation; CI, confidence interval; CRP, C-reactive protein; ECG, electrocardiography. eGFR, estimated glomerular filtration rate (calculated using the Chronic Kidney Disease Epidemiology Collaboration equation); TIA, transient ischemic attack. ${ }^{*} \geq 1 \mathrm{~mm}$ ST-depression in two adjacent leads. ${ }^{\dagger}$ The number of patients with missing data for CRP was $n=261$ $(9.0 \%)$ and for ST-depression $n=265(9.1 \%)$

Table 3. Predictors of acute coronary syndrome among patients with atrial fibrillation and elevated cardiac troponin T.

\begin{tabular}{|c|c|c|c|c|c|}
\hline Univariable Predictors & Odds Ratio $(95 \%$ CI $)$ & $p$ & Multivariable Predictors & Odds Ratio $(95 \% \mathrm{CI})$ & $p$ \\
\hline Age $\geq 75$ years & $0.88(0.56-1.37)$ & 0.561 & Chest pain & $8.29(5.20-13.2)$ & $<0.001$ \\
\hline Male gender & $1.73(1.13-2.66)$ & 0.012 & Coronary artery disease & $2.33(1.42-3.81)$ & 0.001 \\
\hline Hypertension & $1.43(0.88-2.33)$ & 0.148 & $\mathrm{eGFR}<45 \mathrm{~mL} / \mathrm{min} / 1.73 \mathrm{~m}^{2 *}$ & $1.65(1.04-2.63)$ & 0.035 \\
\hline Diabetes mellitus & $1.69(1.11-2.59)$ & 0.015 & & & \\
\hline Hypercholesterolemia & $2.52(1.66-3.84)$ & $<0.001$ & & & \\
\hline Prior myocardial infarction & $3.83(2.50-5.87)$ & $<0.001$ & & & \\
\hline Prior stroke or TIA & $0.67(0.37-1.21)$ & 0.186 & & & \\
\hline Coronary artery disease & $4.68(3.01-7.26)$ & $<0.001$ & & & \\
\hline Heart failure & $0.91(0.56-1.48)$ & 0.711 & & & \\
\hline Chest pain & $11.1(7.19-17.1)$ & $<0.001$ & & & \\
\hline $\mathrm{eGFR}<45 \mathrm{~mL} / \mathrm{min} / 1.73 \mathrm{~m}^{2}$ & $1.57(1.03-2.37)$ & 0.035 & & & \\
\hline $\mathrm{CRP} \geq 50 \mathrm{mg} / \mathrm{L}$ & $0.38(0.18-0.80)$ & 0.009 & & & \\
\hline Troponin $\mathrm{T}, \geq 100 \%$ change & $1.86(0.99-3.48)$ & 0.054 & & & \\
\hline Hemoglobin < $100 \mathrm{~g} / \mathrm{L}$ & $1.06(0.51-2.23)$ & 0.873 & & & \\
\hline ST depression in ECG * & $0.73(0.37-1.43)$ & 0.355 & & & \\
\hline
\end{tabular}

CI, confidence interval; CRP, C-reactive protein; ECG, electrocardiogram; eGFR, estimated glomerular filtration rate (calculated using the Chronic Kidney Disease Epidemiology Collaboration equation); TIA, transient ischemic attack. ${ }^{*}, \geq 1 \mathrm{~mm}$ ST-depression in two adjacent leads. 


\section{Discussion}

Our study demonstrated that minor TnT elevation is a common finding in AF patients presenting at the ED with a wide variety of acute symptoms. Strikingly, ACS or type 1 MI was considered a rare cause of minor TnT elevations, comprising less than one out of twenty patients. Increasing age and multiple co-morbidities were often associated with minor TnT elevations; severe infections, cerebrovascular events, AFs, and decompensated heart failure were the most common final diagnoses at discharge. Most patients with minor TnT elevations were admitted to hospital and minor TnT elevation was a powerful predictor of short-term mortality regardless of the final diagnosis. Importantly, minor TnT elevation by itself did not predict a new ED admission due to ACS within 30 days.

The use of high-sensitivity troponin assays enables safe and robust early exclusion of acute MI in the ED [18,19]. High-sensitivity assays also allow the use of lower thresholds for the diagnosis of type $1 \mathrm{MI}$. The use of this improved sensitivity, however, more than doubles the number of patients with type 2 MI or myocardial injury, but does not seem to improve the prognosis of this new patient group with minor troponin elevations [20]. The present results show that the recommended low rule-out threshold for exclusion of type $1 \mathrm{MI}$ is problematic in clinical practice if applied to patients in whom the degree of MI suspicion is low and there are other factors that might contribute to troponin concentration.

At present, cardiac troponin testing is frequently used in the ED in the absence of symptoms suggestive of ACS [21]. In line with earlier reports [22], the vast majority of minor TnT elevations in this scenario reflected myocardial injury or type $2 \mathrm{MI}$ rather than type $1 \mathrm{MI}$. Earlier reports have shown that if troponin testing is done in all ED patients without selection, elevated cardiac troponin concentrations are frequent, occurring in one in every eight patients [23], and the prevalence of type $1 \mathrm{MI}$ is very low (1.6\%) [24]. Furthermore, high-sensitivity troponin is elevated in over $12 \%$ of ED patients without any clinical suspicion of ACS $[23,24]$.

Minor TnT elevation was a common finding in AF patients presenting to the ED with a variety of acute symptoms. Older age was a strong predictor of elevated TnT and the majority of AF patients older than 75 years had abnormal TnT. If combined with other strong predictors, i.e., either high CRP or impaired renal function, almost all patients had minor TnT elevations irrespective of their final diagnosis (Figure 2), and minor TnT elevations had no diagnostic value in these patient groups. Taking this into consideration, an age-adjusted TnT threshold might prove useful in reducing the rate of unjustified diagnostic efforts to exclude ACS in patients with non-coronary-type symptoms.

As expected, previous history of coronary artery disease and chest pain in the ED were the strongest predictors of ACS in AF patients with minor TnT elevations. Even in this clinical scenario, TnT elevations were considered to be caused by ACS in only a quarter of cases. Our analysis included only patients with serial TnT testing, and it was supposed that dynamic elevation of TnT would increase the specificity of TnT elevations [25-27], although contradictory data has also been published [28]. Disappointingly, dynamic TnT changes (rises or decreases) did not have additional predictive power in the diagnosis of ACS. This observation was, however, not that unexpected since most of the patients with TnT elevations were admitted to hospital because of acute severe illnesses known to cause temporary TnT elevation [29-34].

Patients with type 2 MI or myocardial injury have not been shown to benefit from aggressive antithrombotic treatments or invasive investigation and treatment, unlike patients with type 1 MI. Thus, indiscriminate troponin testing in patients without signs or symptoms consistent with ACS is likely to increase diagnostic uncertainty, with no improvements in patient outcomes. Minor troponin elevations may lead to inappropriate diagnostic calibration in the use of coronary angiography, inappropriate resource use, and lengthened hospital admissions. In the present study, only every fifth coronary angiography revealed coronary changes leading to coronary intervention.

A slew of mechanisms of myocardial injury resulting in troponin release, besides myocardial ischemia, have been characterized. Those mechanisms include cell injury, apoptosis, myocardial strain, inflammation, and/or those decreasing troponin clearance, such as acute or chronic renal impairment $[35,36]$. The causes underlying non-coronary disease-related minor troponin elevation in 
AF are not fully clear; even minor increases in troponin levels are associated with increased mortality risks in several settings [23,37].

Some limitations of our study should be acknowledged. This is an observational study, including comprehensive data collected from AF patients suffering from a variety of acute symptoms and having at least two TnT measurements during the hospital visit. Patients were treated by a heterogeneous group of emergency medicine physicians with no strict institutional protocol for when to test for TnT, but all measurements require a physician order. The final diagnoses were based on real-life adjudication by the treating physicians in the ED and at wards, with all known uncertainties and potential misjudgments. Our intent was to identify AF patients with ACS among patients with minor TnT elevations in the ED, since the specific diagnosis of type $1 \mathrm{MI}$ is problematic in this study setting. Against our preconceptions, diagnostic coronary angiography was seldom used in the diagnostic work-up, increasing the uncertainty and potential missing of ACS cases. It is, however, noteworthy that ACS was extremely uncommon $(0.05 \%)$ during the following month in the patients with elevated TnT during the index ED visit.

\section{Conclusions}

Minor TnT elevations are common in patients with AF presenting at the ED with a variety of symptoms and most of them reflect myocardial injury of type 2 MI. ACS is seldom a cause of minor TnT elevations even in patients with chest pain. Minor TnT elevations do not provide diagnostic value in older patients with multiple co-morbidities. Troponin testing should not be used for unselected ACS screening in ED patients with non-specific symptoms. Clinicians should be aware of the other multiple contributory factors when interpreting elevated cardiac troponin concentrations in their practice.

Supplementary Materials: The following are available online at http://www.mdpi.com/2077-0383/8/11/1963/s1, Table S1: Patient Characteristics According to Primary Diagnosis at Hospital Discharge.

Author Contributions: Conceptualization, K.E.J.A., S.J., I.N., T.O.K., P.P. and T.P.; methodology, I.N, K.E.J.A., S.J. and J.-P.P.; formal analysis, S.J., F.B. and I.N.; investigation, S.J, T.P., F.B., J-P.P., P.P. and K.E.J.A.; resources, K.E.J.A.; data curation, I.N, F.B. and S.J.; writing—original draft preparation, S.J.; writing-review and editing, all authors; visualization, S.J. and F.B.; supervision, K.E.J.A.; project administration, K.E.J.A.; funding acquisition, K.E.J.A.

Funding: This study was funded by The Finnish Foundation for Cardiovascular Research, Helsinki, Finland, and State Clinical Research Fund (EVO) of Turku University Hospital, Turku, Finland.

Acknowledgments: We thank our study coordinator Tuija Vasankari, RN, for her input in study management.

Conflicts of Interest: Samuli Jaakkola: Lecture fees from MSD, Bayer, BMS-Pfizer, AstraZeneca. Tuomas Paana: None. Ilpo Nuotio: None. Tuomas O. Kiviniemi: received research grants from the Finnish Medical Foundation, the Finnish Foundation for Cardiovascular Research, Finnish Cardiac Society, the Emil Aaltonen Foundation, the Maud Kuistila Foundation, and unrestricted grants for investigator-initiated trials from Atricure ltd and Vifor Pharma; received lecture fees from Bayer, Boehringer Ingelheim, MSD, Astra Zeneca, St Jude Medical, and Bristol-Myers-Squibb-Pfizer; a member of the advisory board of Boehringer-Ingelheim, and MSD; Jussi-Pekka Pouru: None. Pekka Porela: Member in the advisory board for Bayer. Fausto Biancari: None. K.E. Juhani Airaksinen: research grants from the Finnish Foundation for Cardiovascular Research, Lecture fees from Bayer, Pfizer and Novartis. Member in the advisory boards for Bayer, Pfizer and Astra Zeneca.

\section{References}

1. Steinberg, B.A.; Kim, S.; Fonarow, G.C.; Thomas, L.; Ansell, J.; Kowey, P.R.; Mahaffey, K.W.; Gersh, B.J.; Hylek, E.; Naccarelli, G.; et al. Drivers of hospitalization for patients with atrial fibrillation: Results from the Outcomes Registry for Better Informed Treatment of Atrial Fibrillation (ORBIT-AF). Am. Heart J. 2014, 167, 735-742. [CrossRef] [PubMed]

2. Thygesen, K.; Alpert, J.S.; Jaffe, A.S.; Chaitman, B.R.; Bax, J.J.; Morrow, D.A.; White, H.D.; Thygesen, K.; Alpert, J.S.; Jaffe, A.S.; et al. Fourth universal definition of myocardial infarction (2018). Eur. Heart J. 2018, $138,618-651$.

3. Carlsson, A.C.; Bandstein, N.; Roos, A.; Hammarsten, O.; Holzmann, M.J. High-sensitivity cardiac troponin $\mathrm{T}$ levels in the emergency department in patients with chest pain but no myocardial infarction. Int. J. Cardiol. 2017, 228, 253-259. [CrossRef] [PubMed] 
4. Shave, R.; Baggish, A.; George, K.; Wood, M.; Scharhag, J.; Whyte, G.; Gaze, D.; Thompson, P.D. Exercise-Induced Cardiac Troponin Elevation: Evidence, Mechanisms, and Implications. J. Am. Coll. Cardiol. 2010, 56, 169-176. [CrossRef]

5. Paana, T.; Jaakkola, S.; Bamberg, K.; Saraste, A.; Tuunainen, E.; Wittfooth, S.; Kallio, P.; Heinonen, O.J.; Knuuti, J.; Pettersson, K.; et al. Cardiac troponin elevations in marathon runners. Role of coronary atherosclerosis and skeletal muscle injury. The MaraCat Study. Int. J. Cardiol. 2019, 295, 25-28. [CrossRef]

6. Januzzi, J.L.; Filippatos, G.; Nieminen, M.; Gheorghiade, M. Troponin elevation in patients with heart failure: On behalf of the third Universal Definition of Myocardial Infarction Global Task Force: Heart Failure Section. Eur. Heart J. 2012, 33, 2265-2271. [CrossRef]

7. Vaduganathan, M.; Bhatt, D.L. Cardiac Troponins in Chronic Kidney Disease: A Marker of Global Cardiovascular Risk. Am. J. Nephrol. 2017, 45, 301-303. [CrossRef]

8. Douketis, J.D.; Crowther, M.A.; Stanton, E.B.; Ginsberg, J.S. Elevated Cardiac Troponin Levels in Patients With Submassive Pulmonary Embolism. Arch. Intern. Med. 2002, 162, 79-81. [CrossRef]

9. Yaghi, S.; Chang, A.D.; Ricci, B.A.; Jayaraman, M.V.; McTaggart, R.A.; Hemendinger, M.; Narwal, P.; Dakay, K.; Mac Grory, B.; Cutting, S.M.; et al. Early Elevated Troponin Levels After Ischemic Stroke Suggests a Cardioembolic Source. Stroke 2018, 49, 121-126. [CrossRef]

10. Frencken, J.F.; Donker, D.W.; Spitoni, C.; Koster-Brouwer, M.E.; Soliman, I.W.; Ong, D.S.Y.; Horn, J.; van der Poll, T.; van Klei, W.A.; Bonten, M.J.M.; et al. Myocardial Injury in Patients With Sepsis and Its Association With Long-Term Outcome. Circ. Cardiovasc. Qual. Outcomes 2018, 11, 004040. [CrossRef]

11. Hijazi, Z.; Wallentin, L.; Siegbahn, A.; Andersson, U.; Alexander, J.H.; Atar, D.; Gersh, B.J.; Hanna, M.; Harjola, V.P.; Horowitz, J.D.; et al. High-Sensitivity Troponin T and Risk Stratification in Patients With Atrial Fibrillation During Treatment With Apixaban or Warfarin. J. Am. Coll. Cardiol. 2014, 63, 52-61. [CrossRef] [PubMed]

12. Naffaa, M.E.; Nasser, R.; Manassa, E.; Younis, M.; Azzam, Z.S.; Aronson, D. Cardiac troponin-I as a predictor of mortality in patients with first episode acute atrial fibrillation. QJM An. Int. J. Med. 2017, 110, 507-511. [CrossRef]

13. Costabel, J.P.; Burgos, L.M.; Trivi, M. The Significance Of Troponin Elevation In Atrial Fibrillation. J. Atr. Fibrillation 2017, 9, 1530. [CrossRef]

14. Jaakkola, S.; Kiviniemi, T.O.; Nuotio, I.; Hartikainen, J.; Mustonen, P.; Palomäki, A.; Jaakkola, J.; Ylitalo, A.; Hartikainen, P.; Airaksinen, K.E.J. Usefulness of the CHA 2 DS 2 -VASc and HAS-BLED Scores in Predicting the Risk of Stroke Versus Intracranial Bleeding in Patients With Atrial Fibrillation (from the FibStroke Study). Am. J. Cardiol. 2018, 121, 1182-1186. [CrossRef]

15. Nuotio, I.; Hartikainen, J.E.K.; Grönberg, T.; Biancari, F.; Airaksinen, K.E.J. Time to Cardioversion for Acute Atrial Fibrillation and Thromboembolic Complications. JAMA 2014, 312, 647-649. [CrossRef] [PubMed]

16. Airaksinen, K.E.J.; Grönberg, T.; Nuotio, I.; Nikkinen, M.; Ylitalo, A.; Biancari, F.; Hartikainen, J.E.K. Thromboembolic complications after cardioversion of acute atrial fibrillation: The FinCV (Finnish CardioVersion) study. J. Am. Coll. Cardiol. 2013, 62, 1187-1192. [CrossRef]

17. von Elm, E.; Altman, D.G.; Egger, M.; Pocock, S.J.; Gøtzsche, P.C.; Vandenbroucke, J.P. STROBE Initiative The Strengthening the Reporting of Observational Studies in Epidemiology (STROBE) statement: Guidelines for reporting observational studies. Lancet (Lond. Engl.) 2007, 370, 1453-1457. [CrossRef]

18. Roffi, M.; Patrono, C.; Collet, J.-P.; Mueller, C.; Valgimigli, M.; Andreotti, F.; Bax, J.J.; Borger, M.A.; Brotons, C.; Chew, D.P.; et al. 2015 ESC Guidelines for the management of acute coronary syndromes in patients presenting without persistent ST-segment elevation. Eur. Heart J. 2016, 37, 267-315. [CrossRef]

19. Twerenbold, R.; Boeddinghaus, J.; Nestelberger, T.; Wildi, K.; Rubini Gimenez, M.; Badertscher, P.; Mueller, C. Clinical Use of High-Sensitivity Cardiac Troponin in Patients With Suspected Myocardial Infarction. J. Am. Coll. Cardiol. 2017, 70, 996-1012. [CrossRef]

20. Shah, A.S.V.; Anand, A.; Strachan, F.E.; Ferry, A.V.; Lee, K.K.; Chapman, A.R.; Sandeman, D.; Stables, C.L.; Adamson, P.D.; Andrews, J.P.M.; et al. High-sensitivity troponin in the evaluation of patients with suspected acute coronary syndrome: A stepped-wedge, cluster-randomised controlled trial. Lancet 2018, 392, 919-928. [CrossRef]

21. Makam, A.N.; Nguyen, O.K. Use of Cardiac Biomarker Testing in the Emergency Department. JAMA Intern. Med. 2015, 175, 67-75. [CrossRef] [PubMed] 
22. Yiadom, M.Y.; Jarolim, P.; Jenkins, C.; Melanson, S.E.F.; Conrad, M.; Kosowsky, J.M. Diagnostic implications of an elevated troponin in the emergency department. Dis. Markers 2015, 2015, 157812. [CrossRef] [PubMed]

23. Lee, K.K.; Noaman, A.; Vaswani, A.; Gibbins, M.; Griffiths, M.; Chapman, A.R.; Strachan, F.; Anand, A.; McAllister, D.A.; Newby, D.E.; et al. Prevalence, Determinants, and Clinical Associations of High-Sensitivity Cardiac Troponin in Patients Attending Emergency Departments. Am. J. Med. 2019, 132, 8-21. [CrossRef] [PubMed]

24. Shah, A.S.V.; Sandoval, Y.; Noaman, A.; Sexter, A.; Vaswani, A.; Smith, S.W.; Gibbins, M.; Griffiths, M.; Chapman, A.R.; Strachan, F.E.; et al. Patient selection for high sensitivity cardiac troponin testing and diagnosis of myocardial infarction: Prospective cohort study. BMJ 2017, 359, j4788. [CrossRef] [PubMed]

25. Morrow, D.A. Clinician's Guide to Early Rule-Out Strategies With High-Sensitivity Cardiac Troponin. Circulation 2017, 135, 1612-1616. [CrossRef] [PubMed]

26. Morrow, D.A.; Cannon, C.P.; Jesse, R.L.; Newby, L.K.; Ravkilde, J.; Storrow, A.B.; Wu, A.H.B.; Christenson, R.H. National Academy of Clinical Biochemistry National Academy of Clinical Biochemistry Laboratory Medicine Practice Guidelines: Clinical Characteristics and Utilization of Biochemical Markers in Acute Coronary Syndromes. Circulation 2007, 115, 356-375.

27. Mahajan, V.S.; Jarolim, P. How to interpret elevated cardiac troponin levels. Circulation 2011, 124, $2350-2354$. [CrossRef]

28. Thelin, J.; Melander, O. Dynamic high-sensitivity troponin elevations in atrial fibrillation patients might not be associated with significant coronary artery disease. BMC Cardiovasc. Disord. 2017, 17, 169. [CrossRef]

29. Wettersten, N.; Maisel, A. Role of Cardiac Troponin Levels in Acute Heart Failure. Card. Fail. Rev. 2015, 1, 102-106. [CrossRef]

30. Zochios, V.; Valchanov, K. Raised cardiac troponin in intensive care patients with sepsis, in the absence of angiographically documented coronary artery disease: A systematic review. J. Intensive Care Soc. 2015, 16, 52-57. [CrossRef]

31. Becattini, C.; Vedovati, M.C.; Agnelli, G. Prognostic Value of Troponins in Acute Pulmonary Embolism. Circulation 2007, 116, 427-433. [CrossRef] [PubMed]

32. Upadhyay, A.; Lopez-Mattei, J.; Kim, P.; Iliescu, C.; Durand, J.-B.; Palaskas, N.; Hassan, S.; Thompson, K.; Mouhayar, E. Diagnostic perfomance of high sensitivity troponin in cancer patients. J. Am. Coll. Cardiol. 2019, 73, 209. [CrossRef]

33. Mochmann, H.-C.; Scheitz, J.F.; Petzold, G.C.; Haeusler, K.G.; Audebert, H.J.; Laufs, U.; Schneider, C.; Landmesser, U.; Werner, N.; Endres, M.; et al. Coronary Angiographic Findings in Acute Ischemic Stroke Patients With Elevated Cardiac Troponin: The Troponin Elevation in Acute Ischemic Stroke (TRELAS) Study. Circulation 2016, 133, 1264-1271. [CrossRef] [PubMed]

34. Agewall, S.; Giannitsis, E.; Jernberg, T.; Katus, H. Troponin elevation in coronary vs. non-coronary disease. Eur. Heart J. 2011, 32, 404-411. [CrossRef]

35. Hammarsten, O.; Mair, J.; Möckel, M.; Lindahl, B.; Jaffe, A.S. Possible mechanisms behind cardiac troponin elevations. Biomarkers 2018, 23, 725-734. [CrossRef] [PubMed]

36. Katus, H.A.; Remppis, A.; Scheffold, T.; Diederich, K.W.; Kuebler, W. Intracellular compartmentation of cardiac troponin $\mathrm{T}$ and its release kinetics in patients with reperfused and nonreperfused myocardial infarction. Am. J. Cardiol. 1991, 67, 1360-1367. [CrossRef]

37. Eggers, K.M.; Jernberg, T.; Lindahl, B. Cardiac Troponin Elevation in Patients Without a Specific Diagnosis. J. Am. Coll. Cardiol. 2019, 73, 1-9. [CrossRef]

(C) 2019 by the authors. Licensee MDPI, Basel, Switzerland. This article is an open access article distributed under the terms and conditions of the Creative Commons Attribution (CC BY) license (http://creativecommons.org/licenses/by/4.0/). 